\title{
CAMPO GERAL TRANSMUTA-SE EM MUTUM
}

Julliany Mucury ${ }^{l}$

Em 2007, o filme MUTUM, uma adaptação da novela Campo Geral, do livro Manuelzão e Miguilim² e dirigido por Sandra Kogut ganhou as telas do cinema. Ana Luiza Martins assina o roteiro com a diretora, que prefere dizer que o filme é mais uma conversa com a obra de Guimarães Rosa do que uma adaptação e assim talvez ela tenha encontrado, na prática, nos efeitos de seu procedimento, o sentido íntimo da mise-en-scène: a colocação em quadro da vida.

Tendo o tempo definido, um recorte temporal contemporâneo, escolheram o sertão de Minas Gerais para inserir a narrativa. E foi nesse espaço que a diretora começou sua peregrinação em busca dos "atores" para seu filme, recrutando um time afiado de não profissionais que atuariam ao lado de outros já consagrados, e que se sentiu imensamente à vontade no cenário em que foram colocados, já que não saíram da vizinhança de suas casas na vida real. Estava pronto o Mutum em transe entre espaço físico presente no mapa e o espaço do filme, isolado no sertão das Gerais. Um laboratório

\footnotetext{
1 Mestranda, Literatura e Outras Áreas do Conhecimento, Departamento de Teoria Literária e Literaturas - TEL, Universidade de Brasília - UnB. Email: jullianymucury@gmail.com

$2 \mathrm{Na}$ verdade, as duas novelas que compõem esta obra foram publicadas em 1956 como parte de Corpo de baile; somente a partir de 1960, quando Corpo de baile se desdobrou em três livros, Manuelzão e Miguilim passou a formar um único volume.
} 
de dois meses na locação foi o fecho para que a integração da equipe com os atores ocorresse, nascia ali a família objeto do drama que constitui o filme.

MUTUM já começa tendo como primeiro plano uma câmera subjetiva, um lampejo do cinema de poesia de Pasolini com sua SIL ${ }^{3}$, resgatado também em diversos momentos em que a "câmera não é sentida" pelo espectador. O público do cinema vê-se inserido em conjunto no lombo de um cavalo, com a câmera a enquadrar a crista do animal, enquanto se sente o sacolejo do trote. É Thiago ${ }^{4}$ e o tio que chegam da crisma do menino, um início fiel ao do livro. Dali em diante a narrativa segue a ordem dos fatos tal qual o original, com determinadas adaptações no sentido mais próximo ao da adequação, por exemplo, na cena em que Felipe corta o pé, a meninada perseguia o louro que voava de árvore em árvore e não um mico, como no original de Rosa. A crença em uma doença que perpassa dias, e que no livro consomem o imaginário de Miguilim, não atinge Thiago. Muitos dos personagens secundários e da trama paralela à principal também tiveram de ser suprimidos, devido ao fato da condensação imposta pela transição de mídias, afinal, as 142 páginas não poderiam ser todas lançadas em uma hora e meia de filme.

Para preservar a narrativa naquilo que faz a identificação acontecer, percebe-se que o cenário, os personagens e o início da película são fiéis, se no decorrer do filme as falas dos personagens correram mais à vontade, despreendidas do vocabulário de Rosa, a frase de Miguilim/Thiago para a mãe de que "o Mutum é um lugar bonito" desencadeia a lembrança do lido no visto e flui o jogo das correspondências. Como muito de Campo Geral é uma incursão no psicológico dos personagens, na telona era preciso que os gestos e olhares dissessem isso e mais um pouco para que a relação ainda existisse. Os atores alcançaram isso na representação.

A montagem do filme respeitou a seqüência narrativa do original - por mais que dela fossem feitos apenas recordes do que era fundamental -, os fatos se sucedem em uma mesma similitude com a obra escrita. Saltos à parte, a montagem linear aplicada no filme mostra que Guimarães Rosa

\footnotetext{
3 A característica fundamental da Subjetiva Indireta Livre - SIL é a de não ser lingüística, mas estilística. Pode definir-se como monólogo interior destituído do elemento conceptual e filosófico abstracto explícito... É, em suma, a SIL que instaura uma tradição possível de língua técnica da poesia no cinema. (PASOLINI, 1982, p. 146).

4 Na película, Miguilim é Thiago e Dito, Felipe, nomes reais dos meninos que interpretam os personagens.
} 
de certa maneira já escrevera um filme, seus personagens e o menino Miguilim carregam uma imensidão em seus silêncios e lacunas. É tudo muito visual, pronto para ser exportado da página escrita para o cinema. O filme primeiro se instala no espaço dessa figura central, Thiago/Miguilim, nas experiências dele com a natureza, com seus irmãos, com a observação do que lhe ia à volta. Brincadeiras, deliciosos sorrisos, lágrimas, olhares perdidos e atentos, as tensões nessa família, gestos de autoritarismo, enfermidades, tudo o que compõe esse pedaço do sertão é na verdade o mundo em escala reduzida.

Por isso o foco em MUTUM são os sons ambientes, a economia de palavras, os gestos e as ações que falam mais, sem, contudo, tornar-se um conceito estético, um arauto da linguagem. Não se apela na duração das cenas nem no plano estático. $\mathrm{O}$ enquadramento diz mais. Miguilim é um personagem complexo, na sua inocência desenrola questionamentos filosóficos densos, quando uma câmera capta a superfície de Thiago, há mais para se ver além da imagem. Sem apelos, o espectador é tocado por uma verdade latente, que brota desse ator mirim sem escola dramática, nem subterfúgios ensaiados, por isso há uma sensibilidade tênue, quase cúmplice, no choro cheio de soluços do garoto.

Kogut foi minimalista para que isso pudesse ser visto em meio a tanta poluição sonora e visual das películas de hoje. A percepção e os sentidos estão em estado de sossego, podem assimilar o que vêem sem serem agredidos por fabulosos "efeitos especiais". É o cinema voltando a ser uma válvula de subversão das relações humanas com o mundo cotidiano. No lugar de acúmulo, vê-se o mínimo. No lugar da velocidade, a cadência. É o garoto de castigo em um canto da sala, ou deitado diante de uma porta. É o olhar suplicante, errante, que clama por algo que sequer entende. Ele pouco vê, pouco compreende, mas sobrevive ao que o cerca, com extrema dignidade.

Thiago é um menino crivado por percepções de mundo atropeladas, talvez ainda incompreensíveis. Ele tem amor e ódio em doses desreguladas, recebe tudo e tenta ao máximo dar seu melhor. Capina com o pai, carinha a mãe e o irmão, brinca com os demais habitantes da casa. Tudo isso faz o enredo andar, e o câncer começa quando o irmão idolatrado do personagem principal é vitimado pelo tétano. $\mathrm{O}$ irmão morre, Thiago assiste a tudo, impotente. Após as peripécias que envolvem as discussões com o pai - na verdade unilaterais, já que sempre o patriarca age com violência cega -, e a aventura de ser um vaqueiro e voltar para um Mutum modificado pela 
ausência definitiva do seu algoz, tudo muda. A cena final reencontra o livro de Rosa, pois a chegada do homem que desvenda o mistério da dispersão de Miguilim/Thiago adentra a tela.

Nesta cena em especial, a diretora registra com planos abertos e fechados o momento mais emocionante de sua película, Thiago pede os óculos ao moço da cidade e começa a olhar ao seu redor, a natureza, os irmãos, a avó e a agregada. O menino não contém a risada diante da revelação que lhe é oferecida, ele vê, claramente, pela primeira vez na vida. Essa quebra de paradigmas, após um amadurecimento interior abrupto, ditado pela violência e pela morte do irmão, é a chave para a ruptura final. Ele aceita deixar o Mutum, despede-se da mãe com candura e encerra um capítulo de sua vida com propriedade.

No plano final, três cavalos se distanciam da câmera, trotando em direção ao fundo do quadro. O filme fica enquanto eles partem. É o fim da jornada e as luzes começam a se acender. O público, tal como o personagem principal, deixa para trás uma história, para viver as que virão.

Para levar a obra de Guimarães Rosa ao cinema, a diretora Sandra Kogut não mediu esforços: mudou-se "com filho e tudo" para o sertão de Minas Gerais, onde acontece a história de MUTUM. Talvez por essa imersão ela tenha conseguido uma tradução bem sucedida de mídias na sua estréia como diretora de ficção. Saltou do universo literário para a tela do cinema buscando ser fiel ao enredo pensado por Rosa para seu Miguilim. Ciente de todas as problemáticas que uma adaptação envolve, desde o condensamento obrigatório imposto pela transição livro/roteiro, a diretora não deixou o fio condutor de MUTUM perder-se em devaneios. Pelo contrário. A ausência de trilha sonora em muitos momentos obriga o público a respirar junto com Thiago, convida a ouvir e aguçar os sentidos, como se todos permanecessem meio míopes por 95 minutos, entregues à magia revelada no retângulo iluminado em meio à escuridão.

Em vários momentos o som fica distante, mas não por uma intencionalidade técnica, de fato parece que neste quesito houve um deslize, que não chega a comprometer o todo em si justamente por haver mais silêncios que sons na película. Entretanto, a diretora parece justificar essa aparente falha ao declarar que buscou o ato de fechar os olhos para ouvir melhor, pois assim o som se torna mais interno, a percepção muda e, mesmo o esforço para identificar o que se está ouvindo, os sons parecem sair "de dentro da cabeça”. O som em MUTUM não seria, portanto, realista, mas um som 
interno. Não seria descritivo, mas sensorial. A análise do título revela a importância desse hiato sonoro: "Mutum quer dizer mudo. Mutum é uma ave negra que só canta à noite". Miguilim/Thiago são de uma mudez reveladora, é ela que explica seu interior e a aversão dos adultos, principalmente do pai, ao seu modo de ser.

A fotografia é um deslumbramento só, Mauro Pinheiro Jr. soube captar o sertão, ele trouxe o imenso árido casado com o interior ressequido dos personagens, a comunhão dos planos abertos e fechados no filme dialogam para testemunhar uma relação patente do externo/interno. Entre seus trabalhos recentes está o longa-metragem Cinema, Aspirinas e Urubus, dirigido por Marcelo Gomes, que recebeu o prêmio de melhor fotografia de longa-metragem pela Associação Brasileira de Cinematografia (ABC), em 2006, é inevitável não pensar que devido a esta experiência vê-se que em Mauro o sertão não foi buscado como paisagem, mas apenas percebido, colhido, na magnitude de sua imensidão árida.

$O$ retrato cru desse lugarejo incrustado entre morros mineiros foi pensado com técnicas cinematográficas que podem ser um indício do passado de Kogut. A feitura de documentários a fez buscar a verdade, não há luz artificial, nem música, os atores são extremamente naturais por serem quase todos não profissionais, à exceção do grupo pai (João Miguel) - mãe (Izadora Fernandes) - tio (Rômulo Braga), eixo de atores consagrados no novo cinema nacional. A diretora prezou de fato um filme mais "parecido com a vida do que com cinema", para ela o espetacular pode estar na simplicidade do cotidiano, o qual ela conseguiu erigir quando optou por mesclar profissionais e não-atores, colocando-os para morar juntos por dois meses na fazenda que serve de cenário para a história.

Para que essa aura de realidade fosse de fato assimilada pela platéia e, principalmente, digerida por ela, apenas três lentes foram usadas nas filmagens. O figurino dos atores locais eram as roupas do dia-a-dia que eles já estavam habituados a usar, e esse desejo por um retrato fiel do sertão, sem a montagem de um fragmento de folclore, recaiu também sobre o roteiro, reescrito todos os dias no set e lido para os atores, que o recriavam com suas próprias palavras. A oralidade também agregou ao conjunto, essa familiaridade com a tradição dos envolvidos trouxe para a tela do cinema um pedaço fidedigno do Mutum.

Como no texto base, a questão do olhar é crucial. Não só pelo alcance restrito da visão do personagem principal, mas em como isso influi em toda 
a interação dele com os demais e o mundo que o cerca. No filme tem-se tomadas fabulosas, grandiosas do sertão, ao mesmo tempo em que close-ups revelam a intimidade do menino e da casa. Essa dicotomia vasto/pequeno é intrínseca ao modo como Guimarães quis retratar o pedaço de Minas Gerais em que vive esta família, sua narrativa parte do âmago de Miguilim, com barreiras impostas pela própria limitação da infância.

O personagem central, Miguilim, vê-se revelado pelas lentes de outrem. E sua surpresa diante da visão amplificada deve-se ao fato de que isso representa um passaporte, uma transição do fosco ao foco. As possibilidades de rever a forma de ver e reconhecer as coisas encanta Miguilim, que ao cabo da narrativa tem sua "visão curta" revelada. O que desvenda atitudes e a própria personalidade do personagem, fechado em si mesmo e inventor de estórias fabulosas. Sua falta de visão clara sobre os aspectos externos do Mutum fez do menino um ente nebuloso, por não conseguir ainda compreender o mundo dos adultos nem percebê-lo pelos olhos, com clareza.

Em alguns trechos do filme percebe-se a necessidade do toque por parte do garoto, suas falhas em enxergar o que lhe era apontado a distâncias grandes, fatores estes reforçados pela alma dispersa e pensativa de Thiago. Para ele, o irmão era uma grande fonte de informações, assim como Rosa e a avó, esta última sempre impregnada de duros preceitos religiosos em suas assertivas. Sandra Kogut não optou pelo óbvio, suas pistas para a dificuldade de visão não recaíram em soluções simples como imagens distorcidas, ela foi além, criou nos detalhes o escopo para lançar o arremate da história.

Na transição entre mídias, Manuelzão e Miguilim sofreu alterações na sintaxe narrativa, proposições, anteposições, retardamentos em funções, para então ressurgir como MUTUM. O público que não leu a obra sentirse-á tentado a procurá-la, pois o filme consegue seduzir com doses certeiras o intelecto de quem o assiste. Se esse é um dos fatores que justificam uma adaptação literária, permitir que um grande número de pessoas tenha acesso às obras-primas da literatura e quiçá procurem o original, vê-se neste caso um intento de sucesso. MUTUM representa muito bem o seu original, ele consegue transmitir o Campo Geral pensado por Guimarães Rosa, com personalidade própria, diálogos realistas e acima de tudo, grandes interpretações. $\mathrm{O}$ tom documentarista deu à película um trunfo, se Sandra Kogut temia a transição para a ficção, acabou tendo a grata surpresa de ver sua 
escola, o documentário, render-lhe bons processos de construção cinematográfica.

MUTUM, de Sandra Kogut, atinge o ponto em que o status da palavra escrita, no caso a de Guimarães Rosa, peso pesado da literatura, encontrou o do silêncio, o das imagens, o de uma poesia latente, conjunta. Por serem meios semióticos diferentes, essa congruência entre o pretendido na linguagem verbal e o alcançado na visual só demonstra que diferentes paradigmas são o instrumento ideal para ir além do nível narrativo em uma análise. 